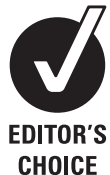

CHOICE

\title{
Alcohol outlet density, levels of drinking and alcohol-related harm in New Zealand: a national study
}

\author{
Jennie L Connor, ${ }^{1}$ Kypros Kypri, ${ }^{1,2}$ Melanie L Bell, ${ }^{3}$ Kimberly Cousins ${ }^{1}$
}

1 Injury Prevention Research Unit, Department of Preventive and Social Medicine, University of Otago, Dunedin, New Zealand ${ }^{2}$ School of Medicine and Public Health, University of Newcastle, Australia

${ }^{3}$ Department of Preventive and Social Medicine, University of Otago, Dunedin, New Zealand

\section{Correspondence to}

Jennie Connor, Department of Preventive and Social Medicine, University of Otago, PO Box

913, Dunedin 9054, New Zealand;

jennie.connor@otago.ac.nz

Accepted 14 September 2010 Published Online First

14 October 2010

\begin{abstract}
Background Previous research shows associations of geographical density of alcohol outlets with a range of alcohol-related harms. Socioeconomic conditions that are associated with both outlet density and alcohol-related outcomes may confound many studies. We examined the association of outlet density with both consumption and harm throughout New Zealand while controlling for indicators of area deprivation and individual socioeconomic status (SES).
\end{abstract}

Methods Individual alcohol consumption and drinking consequences were measured in a 2007 national survey of $18-70$ year olds $(n=1925)$. All alcohol outlets in New Zealand were geocoded. Outlet density was the number of outlets of each type (off-licences (stores that sell alcoholic beverages for consumption elsewhere), bars, clubs, restaurants) within $1 \mathrm{~km}$ of a person's home. We modelled the association of outlet density with total consumption, binge drinking, risky drinking labove New Zealand guidelines) and two measures of effects ('harms' and 'troubles' due to drinking) in the previous year. Logistic regression and zero-inflated Poisson models were used, adjusting for sex, educational level, a deprivation index (NZDep06) and a rurality index. Results No statistically significant association was seen between outlet density and either average alcohol consumption or risky drinking. Density of off-licences was positively associated with binge drinking, and density of all types of outlet was associated with alcohol-related harm scores, before and after adjustment for SES. Associations of off-licences and clubs with trouble scores were no longer statistically significant in the adjusted analysis.

Conclusions The positive associations seen between alcohol outlet density and both individual level binge drinking and alcohol-related problems appear to be independent of individual and neighbourhood SES. Reducing density of alcohol outlets may reduce alcoholrelated harm among those who live nearby.

\section{INTRODUCTION}

The nature of the link between the density of alcohol outlets and alcohol-related harm is of central interest to policymakers considering controls on alcohol availability. More than 50 research papers have been published since the early 1990s finding associations between the spatial density of alcohol outlets and levels of harm, particularly assault ${ }^{1-6}$ but also drink-driving and crashes, $^{7-9}$ pedestrian injury, ${ }^{10}$ child abuse and neglect, ${ }^{11}$ intimate partner violence ${ }^{12}$ and loss of neighbourhood amenity. ${ }^{13} 14$ Most have a crosssectional design, but there have been a few longitudinal studies. Some of these have demonstrated changes in assault rates accompanying changes in outlet density; ${ }^{15-17}$ one study showed a reduction in gonorrhoea incidence accompanying a dramatic reduction in alcohol outlets in Los Angeles ${ }^{18}$ and one study linked changes in numbers of bars and off-licences with changes in car crash injuries. ${ }^{19}$ Recent research by Livingston ${ }^{20}$ in Australia suggests a non-linear relationship between density of hotel (pub) licences and assault where the effect of each additional outlet increases with pre-existing outlet density.

A relationship between outlet density and actual alcohol consumption has been less clearly demonstrated with research to date producing mixed results (recently reviewed by Livingston et $a l^{21}$ and by Popova et $a^{22}$ ). Some studies show a positive association of outlet density with level of consumption at an individual level ${ }^{23} 24$ or aggregate level, ${ }^{25}$ but there is inconsistency. ${ }^{26}$ In California, Pollack and colleagues ${ }^{27}$ found that while the most deprived neighbourhoods had substantially higher outlet density, highest consumption was in the least deprived neighbourhoods. Levels of alcoholrelated harm were not measured.

A few studies have differentiated the effects of different types of outlets on alcohol-related harm. In particular, the density of restaurants has been associated with lower levels of assault ${ }^{2}$ and higher levels of drink driving, ${ }^{78}$ and density of off-licences has been reported to be associated with homicide in New Orleans ${ }^{3}$ and gun assault in Philadelphia. ${ }^{28}$ However, the nature of different types of outlets varies by context. ${ }^{6}$

Among the outlet density studies, a range of methods and measures have been used and some results appear conflicting or, perhaps, contextspecific. ${ }^{16}$ If a causal relationship exists between increasing density of alcohol outlets and alcoholrelated harm, presumably the mediators are of two types: the amount or pattern of drinking; and patterns of social mixing or other elements of the social environment that are not directly due to drinking. It has been suggested that harm could result from outlets attracting antisocial people to the area and loss of social capital, ${ }^{29}{ }^{30}$ or from simply increasing contact between uninhibited young males who become both motivated offenders and potential victims. ${ }^{21}$ However, if the frequently observed association is not causal, it could be the result of confounding by a range of sociodemographic variables that are common to many contexts. That is, increased density of outlets and more alcohol-related harm may co-exist in areas of higher deprivation or may have a common relationship with some other characteristics.

In New Zealand, the last 20 years has seen a relaxation of central controls over supply and 
marketing of alcohol. Since the liberalisation of the Sale of Liquor Act in 1989 the number of licensed premises has more than doubled from 6295 in 1990 to 14183 in June 2009, with an increase in the proportion of alcohol sold by off-licences from $59 \%$ to $68 \%$ of the total. ${ }^{31}$ Two recent studies ${ }^{32}{ }^{33}$ have demonstrated a clear association between overall alcohol outlet density and socioeconomic deprivation in New Zealand, with more alcohol outlets situated in the poorest areas. Hay and colleagues $^{32}$ also demonstrated some variation by type of outlet with only restaurants being more easily accessible in low deprivation areas than in high deprivation areas. The associations with area-level deprivation were not found in rural areas.

Few New Zealand data are available on the association between socioeconomic status (SES) and alcohol consumption. A nationally representative health survey from 2006-2007 demonstrated a shallow J-shaped relationship between quintiles of neighbourhood deprivation and the prevalence of hazardous drinking as measured by an AUDIT score of eight or more. ${ }^{34}$ Lowest levels of hazardous drinking were seen in the second least deprived quintile of the population and the highest levels in the most deprived quintile. An earlier study of young adults from a New Zealand birth cohort ${ }^{35}$ suggested that different indicators of SES (income, education, occupation) varied in their association with different dimensions of drinking. Higher income was found to be associated with greater frequency of drinking, and higher education with lower typical volumes.

The only New Zealand studies to date that have examined the association of alcohol outlet density with alcohol consumption or alcohol-related harm have focused specifically on young people. In a recent study of university students on six campuses, ${ }^{36}$ ecological and individual level associations of outlet density with hazardous consumption and self-reported harmful consequences of drinking were consistently seen. This population is characterised by minimal variation in SES. A second study that focused on urban youth under the legal alcohol purchase age (12-17 years) found outlet density was associated with more frequent drinking and larger typical drinking quantities as well as with increasing levels of area deprivation. ${ }^{37}$

There has been no previous study of outlet density and alcohol consumption or alcohol-related harm in a representative sample of the New Zealand population. Thus, the first aim of this study was to determine the magnitude of any association of alcohol outlet density with alcohol consumption and/or alcoholrelated harm for different alcohol outlet types. The second aim was to examine possible confounding of this association by individual SES and neighbourhood deprivation.

\section{METHODS \\ Design}

A cross-sectional study design was used with individual level data on alcohol consumption and drinking consequences and geospatial measures of proximity to alcohol outlets for the whole of New Zealand.

\section{Survey data}

Individual level data were collected in a 2007 national survey of New Zealand adults' alcohol consumption and self-reported consequences of drinking. Following an invitation letter, questionnaires were sent to a nationally representative sample of New Zealand residents, aged 18-70 years randomly selected from the electoral roll. At least three attempts to follow-up nonresponders were made. Questionnaires were received from 1925 individuals (response rate 49\%).

\section{Drinking variables}

Respondents were asked to indicate the frequency of days on which they drank any alcohol over the past 12 months and the typical number of drinks they consumed per occasion that they drank. Alcohol per year was calculated as the product of the frequency by the typical number of drinks. They were also asked about the frequency of drinking five or more standard drinks on a single occasion (50+g ethanol). Response options were presented as tick boxes with predefined values (daily or almost daily; 3-4 times a week; $1-2$ times a week; $1-3$ times per month; 7-11 times in the last year; $3-6$ times in the last year; twice in the last year; once in the last year; never in the last year). Standard drinks were defined as $10 \mathrm{~g}$ of ethanol. Images of standard drinks in the form of common beverages were provided for reference along with examples of how to convert consumption to standard drinks.

\section{Alcohol-related personal consequences of drinking}

Respondents were presented with two checklists of possible alcohol-related 'harms' and possible alcohol-related 'troubles' that they might attribute to their drinking in the preceding 12 month period (see box 1). Harm and trouble scores were calculated as the sum of the seven harm and seven trouble questions, respectively, each of which could take on values from $0-2$; thus, making the possible range $0-14$ for each measure.

\section{Demographic variables}

Age and sex were self-reported in the survey. Whether the respondent lived in a rural or urban area (rurality) was determined from the respondent's address using the Statistics New Zealand Urban/Rural Profile Classification. ${ }^{38}$

\section{Socioeconomic status}

Self-reported level of educational achievement was used as an indicator of individual socioeconomic position. Small area (or neighbourhood) deprivation was assessed for each respondent using the New Zealand Deprivation Index 2006 (NZDep06). ${ }^{39}$ This index (decile 1-10) indicates the level of deprivation of the area in which the respondent lives relative to the whole country. It is determined at mesh-block level, the smallest area unit used in the national census, covering an average of 100 residents. Mesh-blocks are larger in less densely populated areas. Deprivation scores of mesh-blocks and, therefore, their decile ranking are determined from nine questions asked in the 2006 national census, including levels of income, welfare payments, home ownership, family structure, unemployment, qualifications, overcrowding, telephone access and car access.

\section{Alcohol outlet measures}

Alcohol outlets were categorised as four types: (1) off-licence (including bottle shops, supermarkets, convenience stores), (2) bars/pubs, (3) clubs and (4) restaurants. Data on all liquor licenses active on 31 December 2006 were obtained from the Ministry of Justice and licence addresses were geocoded using GeoStan Map software. ${ }^{40}$ The residential addresses of survey respondents were also mapped and the 'outlet density' for each of the four types of alcohol outlet was defined as the number of outlets of that type within $1 \mathrm{~km}$ of a person's home address.

Ethical approval for the survey was granted by the University of Otago Human Ethics Committee (06/171).

\section{Analysis}

Five outcome measures of alcohol consumption and drinking consequences were considered in the analysis: total alcohol consumed per year (in standard drinks with $10 \mathrm{~g}$ ethanol), risky 


\section{Box 1 Composition of the harm score and trouble score}

\section{Harm score (0-14)}

During the last 12 months, has your drinking had a harmful effect.:

a. on your work, studies or employment opportunities?

b. on your housework or chores around the house?

c. on your marriage/intimate relationships?

d. on your relationships with other family members, including your children?

e. on your friendships or social life?

f. on your physical health?

g. on your finances?

Trouble score $(0-14)$

In the last 12 months, have you had any of the following experiences?

a. Have you had trouble with the law about your drinking and driving?

b. Have you had an illness connected with your drinking that kept you from working on your regular activities for a week or more?

c. Have you lost a job, or nearly lost one, because of your drinking?

d. Have people annoyed you by criticising your drinking?

e. Has your spouse or someone you lived with threatened to leave or actually left because of your drinking?

f. Have you lost a friendship because of your drinking?

g. Have you got into a fight while drinking? Score: $\mathbf{n o}=\mathbf{0}$; yes, once or twice =1; yes, more than twice $=2$.

drinking (defined as consuming more alcohol than the guideline of no more than 14 drinks per week for women and 21 for men), binge drinking (drinking $5+$ drinks on a single occasion once a month or more), alcohol-related harm score $(0-14)$ and alcohol-related trouble score $(0-14)$.

We modelled the effect of alcohol outlet density on risky drinking, binge drinking, harm score, trouble score and alcohol consumed per year. Outlet density for off-license, bars, clubs and restaurants was defined as the number of outlets of each type within $1 \mathrm{~km}$ of a person's home address. We fitted three models for each of the outcomes: (1) unadjusted; (2) adjusted for age, sex and rurality; and (3) adjusted for age, sex, rurality, educational achievement and small area deprivation. Logistic regression was used for each of the binary outcomes (risky drinking, binge drinking), linear regression models were used for alcohol per year and zero-inflated Poisson model ${ }^{41}$ were used for trouble and harm scores. Trouble and harm were calculated as the sum of the seven harm and seven trouble questions each of which could take on values from $0-2$; thus making the possible range 0-14. Negative binomial, over-dispersed Poisson and zero inflated negative binomial models were also considered for trouble and harm but the zero inflated Poisson models provided best fit. Residual spatial auto-correlation was assessed using Moran's I and found not to exist. Abstainers from drinking ( $\sim 7 \%$ of the sample) were included in all analyses. All analyses used SAS version $9.1^{42}$ or Stata version 10.43

\section{RESULTS}

\section{Study population}

There were 1925 respondents to the survey of whom 1770 (92\%) could be geocoded according to their residential address. The demographic characteristics of this study population are presented in table 1.

The mean age of participants was 45.7 years (SD 13.4). There was some under-representation of men, younger people and people from the most deprived neighbourhoods in the sample. The distribution of alcohol consumption per year was highly skewed with a mean of 364 (SD 594) standard drinks but a median of just 156 (interquartile range (IOR) 24-390). Similarly, the number of drinks reported to be consumed on a 'typical day when you drank' had a mean of 3.1 (SD 3.3) and a median of 2 (IOR 1-3) standard drinks.

The prevalence of drinking above the guidelines ('risky drinking'), drinking more than five drinks on a single drinking occasion ('binge drinking') and any positive responses on the alcohol-related trouble and alcohol-related harm scores are presented by demographic characteristics in table 1 . The prevalence of each of these measures was higher in men than in women and in the younger age group. The prevalence of binge drinking, trouble and harm from drinking all decreased with age, but showed no clear pattern by small-area deprivation (NZDep06).

\section{Alcohol outlets}

Of 11129 active alcohol outlets identified throughout New Zealand, 10260 (92\%) were successfully geocoded. After exclusion of a few categories, such as wine makers, wine tasting and conveyances, 9720 outlets were included in the analysis. Of these, off-licences comprised $27 \%(\mathrm{n}=2622)$, bars $26 \%$ (2510), clubs $21 \%$ (2083) and restaurants $26 \%$ (2505). The number of outlets within a $1 \mathrm{~km}$ radius of the participant's home was highly variable, with a small proportion of people living close to a high number of outlets, as seen in table 2 .

\section{Outlet density, drinking and alcohol-related harm}

Table 3 summarises the modelling of the relationships between $1 \mathrm{~km}$ outlet density of four alcohol outlet types and five outcomes of interest. For alcohol consumption per year the estimates are standard drinks per year. For the dichotomous outcomes of risky drinking and binge drinking, ORs from logistic regression models are presented. For the harm and trouble scores, the estimates are relative differences. All of these estimates relate to the association with one additional alcohol outlet of the specified type within $1 \mathrm{~km}$ of place of residence. The estimates are presented first for the unadjusted model, second with adjustment for age, sex and rurality, and third with the addition of a measure of individual SES (educational level) and neighbourhood deprivation (NZDep06).

No significant association was shown between outlet density and the average amount of alcohol consumed per year by participants, although all point estimates from the adjusted models were positive. Similarly, there was no significant association of density of any outlet type and risky drinking (derived from alcohol consumption per year), but adjusted estimates are consistently greater than 1 .

The associations of binge drinking with the density of offlicences, bars and clubs were statistically significant, but not with restaurants. For all types of outlets, adjustment for demographic confounders weakened the association with binge drinking and the additional adjustment for SES strengthened it. The association between binge drinking and off-licence density remained significant in these larger models with a 4.0\% (95\% CI $0.2 \%$ to $7.9 \%$ ) increase in the odds of binge drinking associated with each extra off-licence within $1 \mathrm{~km}$ of home. 
Table 1 Characteristics of the study population and distributions of alcohol-related variables

\begin{tabular}{|c|c|c|c|c|c|c|c|}
\hline & $\mathbf{n} *(\%)$ & $\begin{array}{l}\text { Risky drinking } \\
(\%)\end{array}$ & $\begin{array}{l}\text { Binge drinking } \\
(\%)\end{array}$ & $\begin{array}{l}\text { Any trouble } \\
(\%)\end{array}$ & $\begin{array}{l}\text { Any } \\
\text { harm (\%) }\end{array}$ & $\begin{array}{l}\text { Drinks per typical drinking } \\
\text { day (median, IOR) }\end{array}$ & $\begin{array}{l}\text { Drinks per year } \\
\text { (median, IOR) }\end{array}$ \\
\hline \multicolumn{8}{|l|}{ Gender } \\
\hline Male & 765 (43) & 10 & 25 & 16 & 35 & $2(2,4)$ & $234(48,728)$ \\
\hline \multicolumn{8}{|l|}{ Age group, y } \\
\hline $18-20$ & $50(3)$ & 15 & 51 & 37 & 57 & $5(2,8)$ & $168(48,780)$ \\
\hline $21-30$ & $224(13)$ & 9 & 33 & 25 & 44 & $3(2,6)$ & $120(24,364)$ \\
\hline $51-60$ & $404(23)$ & 7 & 13 & 7 & 25 & $2(1,3)$ & $156(24,546)$ \\
\hline $61-70$ & $278(16)$ & 7 & 8 & 3 & 9 & $2(1,2)$ & $182(24,730)$ \\
\hline \multicolumn{8}{|l|}{ Rural } \\
\hline Yes & $645(37)$ & 7 & 20 & 12 & 28 & $2(1,4)$ & $182(45,546)$ \\
\hline No & $1079(63)$ & 9 & 18 & 12 & 31 & $2(1,3)$ & $156(24,365)$ \\
\hline \multicolumn{8}{|l|}{ NZDep06 } \\
\hline 5 & $193(11)$ & 7 & 15 & 12 & 28 & $2(1,3)$ & $156(24,364)$ \\
\hline 6 & $176(10)$ & 9 & 17 & 12 & 34 & $2(2,4)$ & $156(24,364)$ \\
\hline 7 & $160(9)$ & 8 & 17 & 11 & 28 & $2(2,3)$ & $156(24,364)$ \\
\hline 8 & $130(7)$ & 10 & 22 & 13 & 30 & $2(2,3)$ & $156(24,364)$ \\
\hline 9 & $145(8)$ & 8 & 19 & 11 & 28 & $3(2,4)$ & $78(18,364)$ \\
\hline 10 (most deprived) & $101(6)$ & 8 & 28 & 30 & 46 & $3(2,6)$ & $120(6,360)$ \\
\hline \multicolumn{8}{|l|}{ Education } \\
\hline Primary & $13(1)$ & 7 & 15 & 0 & 8 & $8(2,8)$ & $182(0,240)$ \\
\hline High school $1-3$ y & $306(18)$ & 10 & 20 & 16 & 27 & $2(2,4)$ & $156(24,546)$ \\
\hline High school $>3$ y & $452(26)$ & 8 & 21 & 12 & 27 & $2(2,4)$ & $156(24,365)$ \\
\hline Polytechnic & $372(21)$ & 9 & 19 & 14 & 33 & $2(1,4)$ & $156(27,468)$ \\
\hline
\end{tabular}

*Totals may vary due to missing data.

Significant associations between outlet density and alcoholrelated harm scores were consistently found for all types of outlet and all levels of adjustment in the models. Adjustment for confounders only affected the strength of the association for clubs, where controlling for age, sex and rurality increased the association, and adjustment for SES variables increased it further. Out of the four outlet types, the strongest association with harm scores was seen with the density of clubs where one additional club within $1 \mathrm{~km}$ of home was associated with $5.7 \%$ increase in the score (95\% CI $3.2 \%$ to $8.3 \%$ ). Each off-licence outlet was associated with a $2.3 \%$ increase in harm score and each restaurant or bar with an increase of $0.5 \%$.

Trouble scores were significantly associated with density of offlicences and clubs in the unadjusted models. Controlling for demographics weakened the association for off-licences but not for clubs. Controlling for SES variables weakened both associations.

\section{DISCUSSION}

This cross-sectional study found an association between binge drinking and the density of off-licence liquor outlets within easy

Table 2 Density of alcohol outlets within $1 \mathrm{~km}$ of participants' homes

\begin{tabular}{lllcc}
\hline Outlet type & Median & IOR & Maximum & Mean \\
\hline Off-licence & 1 & $0-3$ & 39 & 2.2 \\
Bar & 0 & $0-2$ & 127 & 2.1 \\
Club & 1 & $0-3$ & 13 & 1.6 \\
Restaurant & 0 & $0-2$ & 105 & 2.5 \\
\hline
\end{tabular}

walking distance of home $(1 \mathrm{~km})$ with a $4 \%$ increase in the odds of binge drinking for every additional outlet. The frequency of self-reported harm due to drinking was positively associated with density of outlets close to home for all types of liquor outlets, but with the largest associations for clubs and off-licences. These findings do not appear to be the result of confounding by basic demographic characteristics or by SES as measured by an index of area deprivation and individual education level. The associations seen between self-reported incidents of trouble due to drinking and the density of off-licences and clubs were at least partly due to confounding by SES.

This study has a number of limitations. No causal inference can be made about the associations described due to the study's cross-sectional design, and self-reported measures may have underestimated both drinking and its harmful consequences. There may also be bias introduced by incomplete response to the survey, although this is more likely to affect the prevalence estimates than the associations modelled. In addition, the sample size of the survey has limited the power of this analysis to identify modest associations and precluded the use of further SES indicators in the models. While five outcomes of interest were modelled for four outlet types, the associations were unlikely to have been identified by chance. The patterns of findings across the models were consistent, whether or not they were statistically significant, and were not unanticipated. The strength and statistical significance of the association of offlicences, but not on-licences, with binge drinking is consistent with the much higher volumes of alcohol sold by off-licence outlets. 
Table 3 Association of one additional alcohol outlet within $1 \mathrm{~km}$ of residence with individual drinking levels and alcohol-related harms

\begin{tabular}{|c|c|c|c|c|c|c|c|c|c|c|}
\hline Outcome & Outlet type & \multicolumn{3}{|c|}{ Model 1: unadjusted estimates } & \multicolumn{3}{|c|}{ Model 2: adjusted for age, sex and rurality } & \multicolumn{3}{|c|}{$\begin{array}{l}\text { Model 3: also adjusted for level of } \\
\text { education and NZDep06 }\end{array}$} \\
\hline & Bar & 1.02 & $(-3.2$ to 5.2$)$ & 0.6 & 2.2 & $(-2.1$ to 6.5$)$ & 0.2 & 2.6 & $(-1.7$ to 6.9$)$ & 0.2 \\
\hline & Club & 2.0 & $(-12.1$ to 16.0$)$ & 0.8 & 5.9 & $(-8.9$ to 20.6$)$ & 0.4 & 8.3 & $(-6.9$ to 23.6$)$ & 0.3 \\
\hline & Restaurant & -0.08 & $(-3.8$ to 3.6$)$ & 0.9 & 1.3 & $(-2.6$ to 5.1$)$ & 0.5 & 1.6 & $(-2.3$ to 5.5$)$ & 0.4 \\
\hline & Bar & 1.004 & (0.981 to 1.027$)$ & 0.8 & 1.007 & (0.984 to 1.030$)$ & 0.6 & 1.008 & (0.985 to 1.032$)$ & 0.5 \\
\hline & Club & 1.039 & (0.957 to 1.128$)$ & 0.4 & 1.050 & (0.966 to 1.142 ) & 0.2 & 1.057 & (0.969 to 1.153 ) & 0.2 \\
\hline & Restaurant & 0.997 & (0.973 to 1.022$)$ & 0.8 & 1.001 & (0.977 to 1.025$)$ & 0.9 & 1.003 & (0.979 to 1.027$)$ & 0.8 \\
\hline \multirow[t]{3}{*}{ Binge drinking $(0,1)$} & Off license & 1.038 & (1.004 to 1.074$)$ & 0.03 & 1.036 & (0.999 to 1.073 ) & 0.05 & 1.040 & (1.002 to 1.079$)$ & 0.04 \\
\hline & Bar & 1.014 & (0.998 to 1.030$)$ & 0.08 & 1.011 & (0.995 to 1.028 ) & 0.2 & 1.013 & (0.996 to 1.031$)$ & 0.1 \\
\hline & Club & 1.056 & (0.998 to 1.118 ) & 0.06 & 1.045 & (0.982 to 1.111$)$ & 0.2 & 1.048 & (0.984 to 1.118$)$ & 0.1 \\
\hline & Club & 1.048 & (1.025 to 1.072$)$ & $<0.0001$ & 1.052 & (1.028 to 1.077 ) & $<0.0001$ & 1.057 & (1.032 to 1.083$)$ & $<0.0001$ \\
\hline & Restaurant & 1.005 & (0.9999 to 1.009 ) & 0.05 & 1.005 & (1.001 to 1.010$)$ & 0.03 & 1.005 & (1.0004 to 1.010$)$ & 0.04 \\
\hline Trouble $(0-14)$ & Off-license & 1.041 & (1.009 to 1.074$)$ & 0.01 & 1.028 & (0.993 to 1.064$)$ & 0.1 & 1.009 & (0.975 to 1.044$)$ & 0.6 \\
\hline & Bar & 1.013 & (0.998 to 1.029 ) & 0.1 & 1.007 & (0.990 to 1.024$)$ & 0.4 & 1.001 & (0.986 to 1.017$)$ & 0.9 \\
\hline & Club & 1.064 & (1.007 to 1.125 ) & 0.03 & 1.063 & (1.006 to 1.124$)$ & 0.03 & 1.034 & (0.976 to 1.095 ) & 0.3 \\
\hline & Restaurant & 1.003 & $(0.987$ to 1.020$)$ & 0.7 & 0.998 & (0.982 to 1.014 ) & 0.8 & 0.998 & (0.983 to 1.013$)$ & 0.8 \\
\hline
\end{tabular}

Strengths of this study include its coverage of all alcohol outlets in the country, in both urban and rural areas, and differentiating between types of outlet that could be expected to have different relationships with drinking and harm. Recent individual level survey data from a national population sample provided contemporaneous data on both alcohol consumption (average and binge) and consequences of drinking. While characterisation of socioeconomic conditions using indicators is necessarily limited, we used an individual indicator from the survey (education) as well as an ecological indicator (NZDep06) in recognition of likely contributions of both individual and neighbourhood level influences on the associations of interest.

Previous studies of outlet accessibility in general populations have largely focused on the association with volume of drinking or with harmful outcomes (including violence) documented in administrative data. Several studies of students ${ }^{13} 14253644$ have found increases in binge drinking and self-reported harms associated with outlet density, but this appears to be the first such study in a national population sample. The measures of harms and troubles used here differed in nature, with troubles being a more objective measure of the impact of drinking on functioning in the wider social environment as well as reflecting greater severity of the incidents described. The frequency of trouble related to drinking (trouble score) was considerably lower in this population sample (table 1) than self-reported harm (harm score); therefore, the power of the study to detect a significant association was more limited. Nevertheless, it appears that the observed associations with trouble scores were confounded by demographic and socioeconomic factors associated with both outlet density and alcohol-related trouble, and these data do not provide evidence for a direct association.

The lack of an association of outlet density with average alcohol consumption levels seen in our study was also observed by Pollack et al in Californian cities ${ }^{27}$ but there were no measures of harmful drinking consequences included in that study. Our findings suggest that, at least within New Zealand communities, density of outlets is associated with increased binge drinking and alcohol-related harm even when average consumption is not significantly affected.

These findings provide support for the hypothesis that the number of liquor outlets within walking distance of home has an effect on patterns of drinking and is associated with harmful consequences of drinking that are not explained by socioeconomic confounding. Unmeasured in this study is the contribution of changes in the social environment accompanying increased density of outlets that may be independent of consumption but contribute to the amount of harm that results from it.

The apparently small increase in binge drinking and harm score per additional alcohol outlet is important when viewed from a public health perspective and in terms of policy options to reduce harm. That the association with increased harm has been found across the whole country where many people live close to very few outlets is an important new finding, but perhaps the difference between having one or two outlets is not very substantial for individuals. However, policy discussions typically focus on restrictions of outlets in higher outlet density areas and in this case the difference between 5 and 15 off-licence

\section{What is already known on this subject}

Previous research has found density of alcohol outlets to be associated with a range of alcohol-related harms. These harms have usually been measured ecologically-for example, as rates of assault or drink-driving crashes-and in urban populations. Confounding by socioeconomic factors may affect many of these studies. Existing evidence of an association between outlet density and level or pattern of alcohol consumption is inconclusive. 


\section{What this study adds}

This study demonstrated associations between the number of offlicences, pubs/bars, clubs and restaurants within $1 \mathrm{~km}$ of home and level of self-reported harm from alcohol in an unselected national population. The number of off-licence outlets within $1 \mathrm{~km}$ was also associated with increased odds of binge drinking. Socioeconomic confounding did not account for much of the association of outlets with harm, which supports the hypothesis of a causal relationship.

outlets is a $48 \%$ increase in the odds of binge drinking and $26 \%$ more alcohol-related harm. If these associations represent causal relationships, the impact of restricting outlet density on binge drinking and harm would be substantial.

Policy makers are currently assessing options to reduce harm from unrestrained drinking in New Zealand as in many other countries. This study confirms that the density of outlets is a legitimate public health concern. There has been a major increase in outlets over the past two decades and a disproportionate growth in the number of off-licences, which appear to be associated with the most harm. This, and the concentration of off-licenses and bars in poorer areas of the country, constitutes a threat to public health that is amenable to change through alcohol policy reform.

Acknowledgements We thank Charlotte Paul, Philippa Howden-Chapman and Rob McGee for comments on an earlier draft.

Funding New Zealand Lottery Grants Board, Department of Internal Affairs, Wellington; Otago University, Dunedin, New Zealand.

Competing interests None declared.

Ethics approval This study was conducted with the approval of the University of Otago Human Ethics Committee 06/171.

Provenance and peer review Not commissioned; externally peer reviewed.

\section{REFERENCES}

1. Gorman DM, Speer PW, Gruenewald PJ, et al. Spatial dynamics of alcohol availability, neighborhood structure and violent crime. J Stud Alcohol 2001;62:628-36.

2. Lipton $\mathbf{R}$, Gruenewald P. The spatial dynamics of violence and alcohol outlets. J Stud Alcohol 2002;63:187-95

3. Scribner R, Cohen D, Kaplan S, et al. Alcohol availability and homicide in New Orleans: Conceptual considerations for small area analysis of the effect of alcohol outlet density. J Stud Alcohol 1999;60:310-16.

4. Scribner RA, MacKinnon DP, Dwyer JH. The risk of assaultive violence and alcohol availability in Los Angeles county. Am J Public Health 1995;85:335-40.

5. Zhu L, Gorman DM, Horel S. Alcohol outlet density and violence: A geospatial analysis. Alcohol Alcohol 2004;39:369-75.

6. Gruenewald P, Freisthler B, Remer L, et al. Ecological models of alcohol outlets and violent assaults: crime potentials and geospatial analysis. Addiction 2006;101:666-77.

7. Gruenewald PJ, Johnson FW, Treno AJ. Outlets, drinking and driving: A multilevel analysis of availability. J Stud Alcohol 2002;63:460-8.

8. Scribner RA, MacKinnon DP, Dwyer JH. Alcohol outlet density and motor vehicle crashes in Los Angeles County cities. J Stud Alcohol 1994;55:447-53

9. Treno AJ, Grube JW, Martin SE. Alcohol availability as a predictor of youth drinking and driving: a hierarchical analysis of survey and archival data. Alcohol Clin Exp Res 2003;27:835-40.

10. LaScala EA, Johnson FW, Gruenewald P. Neighbourhood characteristics of alcoholrelated pedestrian injury collisions: a geospatial analysis. Prev Sci 2001;2:123-34.
11. Freisthler B, Needell B, Gruenewald PJ. Is the physical availability of alcohol and illicit drugs related to neighborhood rates of child maltreatment? Child Abuse Negl 2005;29:1049-60.

12. McKinney CM, Caetano R, Harris TR, et al. Alcohol availability and intimate partne violence among US couples. Alcohol Clin Exp Res 2009;33:169-76.

13. Chaloupka F, Grossman M, Saffer H. The effects of price on alcohol consumption and alcohol-related problems. Alcohol Res Health 2002;26:22-34.

14. Wechsler H, Lee JE, Hall J, et al. Secondhand effects of student alcohol use reported by neighbors of colleges: The role of alcohol outlets. Soc Sci Med 2002; 55:425-35

15. Gruenewald $\mathbf{P J}$, Remer L. Changes in outlet densities affect violence rates. Alcohol Clin Exp Res 2006;30:1184-93.

16. Livingston M. A longitudinal analysis of alcohol outlet density and assault. Alcoho Clin Exp Res 2008;32:1074-9.

17. Norstrom T. Outlet density and criminal violence in Norway, 1960-1995. J Stud Alcohol 2000;61:907-11.

18. Cohen DA, Ghosh-Dastidar B, Scribner R, et al. Alcohol outlets, gonorrhea, and the Los Angeles civil unrest: a longitudinal analysis. Soc Sci Med 2006;62:3062-71.

19. Treno AJ, Johnson FW, Remer LG, et al. The impact of outlet densities on alcoholrelated crashes: a spatial panel approach. Accid Anal Prev 2007;39:894-901.

20. Livingston M. Alcohol outlet density and assault: A spatial analysis. Addiction 2008;103:619-28.

21. Livingston M, Chikritzhs T, Room R. Changing the density of alcohol outlets to reduce alcohol-related problems. Drug Alcohol Rev 2007;26:557-66.

22. Popova S, Giesbrecht N, Bekmuradov D, et al. Hours and days of sale and density of alcohol outlets: Impacts on alcohol consumption and damage. Alcohol Alcohol 2009;44:500-16

23. Scribner $\mathbf{R}$, Mason $\mathrm{K}$, Theall $\mathrm{K}$, et al. The contextual role of alcohol outlet density in college drinking. J Stud Alcohol Drugs 2008;69:112-20.

24. Scribner RA, Cohen DA, Fisher W. Evidence of a structural effect for alcohol outle density: A multilevel analysis. Alcohol Clin Exp Res 2000;24:188-95.

25. Weitzman ER, Folkman A, Folkman MPHKL, et al. The relationship of alcohol outle density to heavy and frequent drinking and drinking-related problems among college students at eight universities. Health Place 2003:9:1-6.

26. Schonlau M, Scribner R, Farley TA, et al. Alcohol outlet density and alcohol consumption in Los Angeles county and southern Louisiana. Geospat Health 2008:3:91-101.

27. Pollack CE, Cubbin C, Ahn D, et al. Neighbourhood deprivation and alcohol consumption: does the availability of alcohol play a role? Int J Epidemiol 2005; 34:772-80

28. Branas CC, Elliott MR, Richmond TS, et al. Alcohol consumption, alcohol outlets, and the risk of being assaulted with a gun. Alcohol Clin Exp Res 2009;33:906-15

29. Theall KP, Scribner R, Cohen D, et al. Social capital and the neighborhood alcohol environment. Health and Place 2009;15:323-32.

30. Gruenewald $\mathbf{P}$. The spatial ecology of alcohol problems: niche theory and assortative drinking. Addiction 2007:102:870-8.

31. New Zealand Law Commission. Alcohol In Our Lives:An Issues Paper On The Reform Of New Zealand's Liquor Laws. Wellington: NZ Law Commission 2009:17-27

32. Hay GC, Whigham PA, Kypri K, et al. Neighbourhood deprivation and access to alcohol outlets: A national study. Health Place 2009;15:1086-93.

33. Pearce J, Day P, Whitten K. Neighbourhood provision of food and alcohol retailing and social deprivation in urban New Zealand. Urban Policy Res 2008;26:213-27.

34. Ministry of Health. A Portrait of Health: Key results of the 2006/07 New Zealand Health Survey. Wellington: Ministry of Health, 2008

35. Casswell S, Pledger M, Hooper R. Socioeconomic status and drinking patterns in young adults. Addiction 2003:98.

36. Kypri K, Bell ML, Hay GC, et al. Alcohol outlet density and university student drinking: a national study. Addiction 2008;103:1131-8.

37. Huckle T, Huakau J, Sweetsur P, et al. Density of alcohol outlets and teenage drinking: Living in an alcogenic environment is associated with higher consumption in a metropolitan setting. Addiction 2008;103:1614-21.

38. Bayley A, Goodyear R. An Urban/Rural Profile. Stat N Z 2001

39. Salmond C, Crampton P, Atkinson J. NZDep 2006 Index of Deprivation. Wellington: Department of Public Health, University of Otago, 2007.

40. Critchlow Limited. Geostan Map. Christchurch: Critchlow Limited, 2006

41. Cameron A, Trivedi P. Regression Analysis of Count Data. Cambridge: Cambridge University Press, 1998

42. SAS Institute Inc. SAS 9.1 Help and Documentation. Cary, NC: SAS Institute Inc 2000-2004.

43. StataCorp. Stata Statistical Software: Release 10. College Station, TX: StataCorp LP 2007.

44. Kuntsche EN, Kuendig H. Do school surroundings matter? Alcohol outlet density, perception of adolescent drinking in public, and adolescent alcohol use. Addict Behav 2005:30:151-8. 